\title{
Desenvolvimento nacional e gestão de recursos hídricos no Brasil
}

National Development and Management of Water Resources in Brazil Développement national et gestion des ressources hydriques au Brésil

\section{Antônio loris}

\section{OpenEdition}

\section{Journals}

Edição electrónica

URL: http://journals.openedition.org/rccs/329

DOI: $10.4000 /$ rccs.329

ISSN: $2182-7435$

\section{Editora}

Centro de Estudos Sociais da Universidade de Coimbra

Edição impressa

Data de publição: 1 Junho 2009

Paginação: 23-41

ISSN: 0254-1106

Refêrencia eletrónica

Antônio loris, "Desenvolvimento nacional e gestão de recursos hídricos no Brasil », Revista Crítica de Ciências Sociais [Online], 85 | 2009, colocado online no dia 01 dezembro 2012, criado a 19 abril 2019. URL : http://journals.openedition.org/rccs/329 ; DOI : 10.4000/rccs.329 


\title{
ANTÔNIO IORIS
}

\section{Desenvolvimento nacional e gestão de recursos hídricos no Brasil}

\begin{abstract}
A gestão de recursos hídricos está relacionada não somente a práticas e tecnologias diretamente ligadas à distribuição, uso e conservação de água, mas também a questões mais profundas de desenvolvimento nacional e representação política. A experiência brasileira, desde o período colonial até à recente liberalização económica, demonstra vividamente essa complexidade histórico-geográfica. Durante a fase desenvolvimentista, caracterizada pela substituição de importações, grande obras de engenharia hidráulica foram executadas como base da expansão urbana e agro-industrial. O alto custo ambiental e as insuficiências de tais iniciativas passaram a exigir um esforço de mitigação e regulação mais rigoroso. Contudo, o novo marco legal introduzido em 1997, apesar de mudanças discursivas e simbólicas importantes, em grande medida reproduz a mesma racionalidade elitista e tecnocrática do passado. Alternativas efetivas aos problemas de gestão de recursos hídricos requerem processos mais democráticos e equitativos, que inevitavelmente fazem parte de mudanças sociais mais amplas.
\end{abstract}

Palavras-chave: gestão de recursos hídricos, ecologia política, desenvolvimento nacional, neoliberalismo, Brasil.

Abundância e disponibilidade de água são características das terras brasileiras que chamavam a atenção já dos primeiros viajantes portugueses, como no relato de Pêro Vaz de Caminha: "Águas são muitas; infinitas. Em tal maneira é graciosa [a terra] que, querendo-a aproveitar, dar-se-á nela tudo; por causa das águas que tem!”. A percepção da água como expressão da riqueza nacional não se restringiu, contudo, a construções poéticas e relatos épicos, mas marcou a evolução socioeconômica ao longo dos cinco séculos de história. O fato de contar com água em profusão, muito mais que qualquer outro país americano, influenciou a colonização do território, a formação cultural e, de resto, a própria relação entre sociedade e natureza. A utilização de rios, aquíferos, lagoas e manguezais na produção de mercadorias e na organização da atividade produtiva gradualmente transformou o elemento natural água em um recurso dotado de valor económico. Mas a 
intensa exploração dos estoques de água deixou profundas sequelas e provocou uma extensa degradação ambiental - por exemplo, a poluição decorrente de uma descarga diária de $82 \%$ dos esgotos sem qualquer tratamento ou uma demanda por água muito além dos limites hidrológicos em várias bacias do Atlântico Nordeste, do Leste e do Paraná (MMA, 2006). ${ }^{1} \mathrm{O}$ abastecimento de água e o saneamento atendem, actualmente, $91,3 \%$ e $57,4 \%$ das residências urbanas, respectivamente, mas continua a haver importantes desigualdades regionais, sociais e até mesmo raciais (IPEA, 2008).

Este texto pretende discutir as causas e tendências dos problemas de uso e de conservação dos recursos hídricos no Brasil, levando em conta as pressões e os limites do desenvolvimento econômico. O ponto de partida para nossa análise é o reconhecimento de uma certa hesitação entre os teóricos atuais para contextualizar as questões de recursos hídricos como componente de trajetórias histórico-geográficas e socionaturais mais amplas. Tal relutância, demonstrada pelo predomínio de uma linguagem hidrológica e economicista, vem constrangendo a formulação de soluções efetivas aos problemas que têm uma ontologia essencialmente sociológica e civilizacional. A experiência recente de reformas institucionais no Brasil está restrita, até agora, a avanços em termos de procedimentos regulatórios e reordenamento administrativo, mas permanece de olhos fechados a injustiças ambientais e à hierarquização de oportunidades. Sem estabelecer uma relação direta com a realidade concreta dos problemas de recursos hídricos, o tratamento convencional continua centrado nos sintomas, ao invés de diagnosticar a extensão da doença.

Para se compreender o papel do uso da água no desenvolvimento econômico é necessário perceber o detalhe e desvendar as subtilezas encobertas por 'verdades' longamente consolidadas, mas imiscuídas nas engrenagens invisíveis de poder. O aforismo proposto por Mollinga (2008), que "gestão de recursos hídricos é um ato inerentemente político", serve de linha mestra da análise do caso brasileiro. Nosso método de trabalho, portanto, deverá situar as questões da água como resultado de desigualdades historicamente estabelecidas quanto ao acesso a recursos e à distribuição de impactos ambientais. Para se chegar a um estudo consequente dos problemas de gestão de recursos hídricos, deve-se identificar responsabilidades coletivas, mas profundamente diferenciadas, entre todos os grupos sociais que interagem em um dado território. Nesse sentido, é falaciosa qualquer equivalência de tratamento entre indivíduos e classes sociais desiguais, como fica

\footnotetext{
${ }^{1}$ Informações sobre a situação ecológica e socioeconômica das bacias hidrográficas brasileiras podem ser encontradas em MMA (2006).
} 
implícito na nova legislação brasileira de recursos hídricos. Como alertado por Marx e Engels (1974), a concepção liberal de sociedade civil nada mais é do que o resultado da consolidação da propriedade privada e da desintegração de regimes coletivistas de produção. Tal observação tem repercussões extremamente atuais, quando se verifica que as políticas públicas contemporâneas aprofundam a reificação e privatização de recursos que são, antes de tudo, bens coletivos.

\section{Água, economia e desenvolvimento}

A história econômica do Brasil está inserida no largo experimento de exploração de recursos e produção de mercadorias ditado pelas exigências do regime capitalista transposto para o Novo Mundo. Mesmo no início do período colonial, notadamente com a produção de açúcar e o emprego de mão-de-obra escrava, a base da economia brasileira já era essencialmente capitalista, com todos os factores de produção e do fluxo de renda sujeitos à expressão monetária (Furtado, 2007: 87). Essa condição preponderantemente capitalista veio a influenciar, em menor ou maior grau, toda a formação social e, particularmente, a evolução do uso da água no Brasil. Ao invés de simples estoque de riqueza, capital é 'valor em movimento' e sua acumulação é o processo pelo qual ocorre a multiplicação de valor através da exploração e alienação do trabalho empregado na produção de mercadorias (Smith, 2007). A regra fundamental do sistema capitalista é a de que o capital deve gerar mais capital, o que acontece através do lucro obtido com a produção de mercadorias. Para se identificar a função que o meio natural desempenha, incluindo os estoques de água, na economia capitalista, é necessário compreender os conflitos de interesse em torno da composição da mercadoria e as transferências de valor a ela relacionadas. É justamente essa generalização da existência das mercadorias que faz a organização capitalista tornar-se socialmente necessária (Marx, 1996: 83).

Ao invés de diminuir em importância, uma vez que pressionada pelo avanço do capitalismo industrial, a exploração da natureza segue mantendo um papel econômico essencial como garantidor das "condições de produção" (Marx, 1998: 612). Especialmente por essa razão, para o regime capitalista, os valores intrínsecos do meio natural devem ser considerados não em si mesmos, mas em relação às necessidades de circulação de capital. A terra (i.e., a natureza) é um repositório de 'valores intrínsecos' (i.e., matérias-primas, propriedades ecológicas ou 'forças na natureza', como o potencial hidreléctrico) que são conectados ao processo produtivo através do trabalho humano e passam a demonstrar 'valor de uso' a ser aplicado na expressão do 'valor de troca' (cf. Kovel, 2002). Por exemplo, o valor hidro- 
lógico (valor intrínseco) da água passa a manifestar um valor produtivo (valor de uso) ao servir como matéria-prima para a agroindústria (meio de produção) e como veículo para diluição de efluentes (condição de produção). O produto dessa atividade produtiva, a mercadoria final, encerra uma duplicidade de valor de uso e valor de troca, o que permite a apropriação final de lucro por parte daquele que a controla, mesmo que sem a devida remuneração dos trabalhos que tomaram parte na produção. ${ }^{2}$

Com o avanço das relações capitalistas, conforme descrito por Marx, o 'metabolismo' entre sociedade e natureza passa por uma 'ruptura' (metabolic rift) em função da crescente mercadorização (commodification) de recursos e processos da natureza (Foster, 2000). Ao tratar os recursos naturais, a água em particular, como mais uma forma de mercadoria (ainda que 'fictícias', porque não produzidas para serem diretamente transacionadas no mercado - cf. Polanyi, 2001), o regime capitalista imprime sobre a natureza uma lógica reducionista e que é intrinsecamente antagónica a qualquer imposição de limites de caráter social sobre a exploração do ambiente e a tendência de acumulação ilimitada de capital. Isso significa dizer que os impactos ambientais estão inscritos no próprio DNA do regime capitalista, pois ao precisar expandir-se para não perecer e ao fazê-lo, arrasta consigo um manto pesado de degradação socioambiental. Essa faculdade inerentemente expansionista do capitalismo conduz a uma dupla contradição: não somente o confronto entre os trabalhadores e as relações de trabalho, mas também uma discordância mais ampla entre as forças de produção e as próprias condições de produção (O'Connor, 1998).

A inescapável contradição entre o capitalismo e sua base natural descreve claramente a trajectória de uso dos recursos hídricos no Brasil, como se verá em detalhe mais adiante. Ainda durante a colonização, os rios foram estrategicamente utilizados como via principal de acesso ao interior, em um processo que, na busca de riquezas minerais e escravos indígenas, gradativamente distendeu a fronteira colonial luso-espanhola. O controle sobre as reservas hídricas teve influência sobre a disposição dos primeiros núcleos urbanos, engenhos, fazendas e fortificações militares (ANA, 2007). Com a chegada das indústrias e da crescente urbanização, a partir do final do século XIX, a geração hidreléctrica e o abastecimento público passaram a demandar volumes cada vez maiores, apesar de ser a agricultura irrigada o setor responsável pelo maior percentual de água utilizada. Seja na fase predominantemente agrícola, seja no período marcadamente industrial,

${ }^{2}$ Cabe ressaltar que a teoria Marxista do valor é fundamentalmente uma expressão da relação de classes (Harvey, 2006: 24). 
em que pesam diferenças históricas, a água sempre serviu como matéria- prima essencial e elemento básico do processo produtivo. O desenvolvimento brasileiro, porém, ao aumentar sua dependência de recursos naturais - ao mesmo tempo em que os destrói e despreza as populações que lhes estão mais diretamente associadas - segue o desconcertante caminho da insustentabilidade.

O paradoxo da insustentabilidade, que caracteriza o processo de crescimento econômico e a exploração de recursos hídricos no Brasil, corresponde ao dilema central do capitalismo, qual seja, a formação de crises previsíveis e recorrentes. Tais crises, segundo os neomarxistas, têm não somente uma importância econômica e social, mas também uma dimensão ambiental e ética de igual relevância. ${ }^{3}$ Por outro lado, as forças e os agentes capitalistas demonstram uma impressionante capacidade de superação dessas mesmas crises, ainda que as soluções de mercado apresentem uma limitada efetividade (Žižek, 2008). No que concerne ao meio ambiente, existe hoje um esforço internacional (denominado de 'capitalismo verde' ou 'modernização ecológica') para fazer com que a natureza deixe de ser apenas objeto de extração de valor de uso e se torne diretamente detentora de valor de troca, sem a necessidade do consumo de recursos naturais. Isso significa, expandindo o raciocínio de Polanyi, que os elementos da natureza deixam progressivamente de ser 'mercadorias fictícias' para se tornarem 'quase-mercadorias', como no caso da venda de serviços ecológicos através de mecanismos de mercado (e.g. mercado de carbono, pagamento pela biodiversidade, ecoturismo, etc.). Essas novas mercadorias permitem que a conservação e a recuperação da natureza se tornem estratégias diretas de acumulação de capital; são mercadorias simultaneamente escavadas (em termos de valor de troca) de relações socionaturais preexistentes e, como parte de sua produção, são reinseridas ou permanecem latentes em uma natureza socializada (Smith, 2007: 17).

A expansão capitalista sobre a natureza não se dá, portanto, de modo linear ou ininterrupto, mas reflete conjunturas específicas. Da mesma forma, as transformações ecológicas relacionadas à produção e à acumulação capitalista equivalem a dinâmicas geográficas em permanente mutação. Essa incorporação do espaço na lógica de acumulação capitalista acontece através de um fluxo de pressões que simultaneamente induzem à equalização e à diferenciação, em uma complexa dialética de aproximação e antagonismo entre o local e o global (Smith, 2008). A preponderância de um determinado

\footnotetext{
${ }^{3}$ Para uma discussão de justiça social segundo uma perspectiva de classe e levando em conta a questão espacial, ver Harvey (1973).
} 
grupo social sobre outro ocorre através do exercício da hegemonia, mantida por meio de relações de consentimento e coerção, as quais são consolidadas em instituições revestidas como expressão do senso comum (Gramsci, 1971). Existe, por exemplo, uma relação estreita entre circulação de capital, circulação de água e fluxos de poder político, o que é ainda mais evidente nos precários sistemas distribuição das grandes cidades dos países em desenvolvimento (Swyngedouw, 2004). Buscando uma aproximação entre o conceito gramsciano de hegemonia e a noção da fluidez do poder de Foucault, Ekers e Loftus (2008) argumentam que as técnicas de poder estão imbricadas tanto na experiência diária da população com a problemática da água, quanto estão relacionadas ao controle político do aparelho estatal. Contudo, as populações e os indivíduos envolvidos não se submetem inteiramente ao poder dominador, mas reagem crítica e criativamente de acordo com suas possibilidades (Hickey e Mohan, 2004).

Portanto, podemos afirmar que o entendimento acerca do uso e conservação dos recursos hídricos é resultante do funcionamento e das disputas internas da relação sociedade-natureza sob influência das instituições capitalistas. Se, por um lado, é importante reconhecer a exploração de recursos naturais como sendo uma das características centrais do desenvolvimento nacional, por outro, deve-se evitar formulações simplistas sobre a geração de injustiças sociais e impactos ambientais associados ao crescimento da economia. As duas próximas secções deste texto tentarão estabelecer uma continuidade dialética entre a 'fase desenvolvimentista' (em que o uso da água serviu basicamente como matéria-prima e fonte indireta de acumulação) e a 'fase neoliberal' contemporânea (para a qual a água continuou a ser empregada como insumo fundamental da atividade produtiva, mas a própria gestão torna-se também objeto de transacções comerciais e fonte direta de acumulação). As contradições e consequências socionaturais de cada fase serão esquematicamente apresentadas com o propósito de demonstrar uma linha de coerência, apesar de diferenças históricas e geográficas, na forma como a água vem sendo incorporada na economia, produzindo uma hierarquia de beneficiários e crescente degradação ecológica.

\section{Fase desenvolvimentista: A água como mecanismo indireto de acumulação}

A exploração de recursos alegadamente abundantes com o propósito de fomentar o crescimento econômico foi uma das premissas centrais de políticas públicas voltadas à água e aos rios brasileiros. No período colonial, a prática de amealhar e sacrificar a natureza, como de resto as populações nativas, a serviço da produção de riqueza privada, correspondia à postura expansionista e mercantil da civilização renascentista, inspirada em uma 
ética baconiana e apoiada por avanços científicos em diversas áreas. Em contraste com as paisagens ásperas e decrépitas da Europa, o novo mundo era ilusoriamente descrito como uma terra de farturas e primaveras sem fim. Era a própria 'visão do paraíso' solenemente à espera de ser conquistado (Holanda, 2000). A organização política e social da colónia, zona central de acumulação do império português a partir do século XVIII, estruturava-se sobre uma dupla exploração da natureza e da mão-de-obra escrava (Prado Júnior, 1977). Após a independência em 1822 e com o declínio da atividade mineradora e açucareira, a produção de café consolidou-se como principal atividade exportadora, especialmente, no Segundo Reinado. $\mathrm{Na}$ mesma década, o país esteve envolvido no maior confronto militar de sua história - a Guerra do Paraguai - que foi, em larga medida, uma disputa hidropolítica em torno do controle da navegação na Bacia do Rio da Prata. Enquanto no Sul e Sudeste - por conta da urbanização e início da industrialização - a água era factor de desenvolvimento, no Nordeste as secas sucessivas eram motivo de escândalo; mas ao invés de serem apenas a manifestação de fenómenos atmosféricos ocasionais, as secas nordestinas eram, antes de tudo, resultado de pressões do imperialismo britânico e incompetência do Estado brasileiro (Davis, 2004).

Ao final do século XIX, a competição entre novas e antigas estruturas político-econômicas, bem como a emergência de interesses regionais e setoriais díspares, desencadeou a revolta republicana, em 1889, de feição marcadamente oligárquica. $\mathrm{Na}$ transição para o século $\mathrm{xx}$, apenas os principais núcleos urbanos eram servidos por poucas empresas públicas de abastecimento de água e energia hidreléctrica, normalmente privadas e de capital inglês, que atendiam praticamente as zonas habitadas pelos moradores mais aquinhoados. A onda modernizadora teve outro momento decisivo na chamada Revolução de 1930, resultado de uma aliança tácita, de certo modo contraditória, mas que se justificava perfeitamente dentro do sistema oligárquico regional, entre fazendeiros do café, banqueiros e industrialistas. Pressionado pela queda do preço do café e por uma severa depreciação cambial, o governo Vargas adotou uma política anticíclica agressiva e que foi suficiente para consolidar uma industrialização baseada na substituição de importações (Furtado, 2007). O governo central, protagonista principal do processo modernizador, passou a promover uma importante reorganização dos órgãos públicos no sentido de atender às novas demandas econômicas e sociais. Ainda no início da fase industrialista, foi aprovado o Código de Águas de 1934, o qual serviu como alicerce jurídico para os investimentos públicos e privados levados a efeito nas cinco décadas seguintes. 
Com a crescente industrialização, a demanda por energia eléctrica passou a aumentar exponencialmente, requerendo novas e maiores barragens que permitissem explorar o potencial hidreléctrico. Após um interregno, devido à Segunda Guerra, na década de 1950, foram retomados os investimentos públicos, que foram, em grande medida, financiados por empréstimos externos. Diversas empresas estaduais foram criadas para administrar a expansão da geração eléctrica e, entre 1930 e 1960, a potência hidreléctrica instalada passou de 615, 2 MW para 3.642,0 MW (cf. ANEEL, 1999). Com o esgotamento dos locais mais próximos dos grandes centros no Sudeste, outras bacias hidrográficas tiveram de ser consideradas, especialmente em direção ao Sul e ao Nordeste. As novas barragens passaram a servir não somente para hidroeletricidade, mas também para controle de cheias e para irrigação (Barbosa e Braga, 2003). Os censos demográficos mostram que a população passou de 41 milhões em 1940 para 70 milhões em 1960. O processo de crescimento e a rápida transformação dos espaços urbanos, decorrendo do dinamismo geográfico do capital, representaram um imenso desafio para o aparelhamento dos serviços de abastecimento de água, saneamento básico e drenagem pluvial. A irrigação agrícola de caráter comercial teve início no Sul do país, mas até ao início da década de 1950, havia apenas 400 mil hectares irrigados no país. Desde então, políticas nacionais de incentivo fizeram com que a área de irrigação crescesse a uma taxa de $30 \%$ por década e se expandisse para outras regiões do país, especialmente para o Sudeste e Nordeste. Mesmo assim, no semi-árido, a falta de água continuava a afectar largas parcelas da população regional de modo semelhante ao que ocorria desde o século anterior.

Os vetores de desenvolvimento desencadeados desde a década de 1930 - baseados essencialmente em investimentos públicos, substituição de importações, expansão do mercado interno e rígido controle nas mãos do governo federal, fatores esses que formavam um todo coerente, ainda que não monolítico, a serviço de um projeto político com interesses de classe específicos e cuja expressão maior foi o Plano de Metas de Juscelino Kubitschek, com seus objectivos ambiciosos em termos de ganhos de eficiência econômica e interconexão com o mercado capitalista internacional (Ioris, 2007a) - receberam grande impulso após a instalação do regime ditatorial em primeiro de abril de 1964. O contexto geopolítico da Guerra Fria, associado à abundância de petrodólares na banca mundial, proporcionou condições altamente favoráveis para investimentos maciços em obras de infraestrutura. As grandes obras produziam não somente empregos e circulação temporária de capital, mas serviam de instrumentos legitimadores do regime. Entre as décadas de 1960 e 1980, acelerou-se o ritmo de cons- 
trução de hidreléctricas, com uma taxa média anual de $16 \%$ de crescimento da potência instalada (comparada com 6\% entre as décadas de 1930 e 1950 - cf. ANEEL, 1999). Nesta fase, houve uma progressiva interligação eléctrica entre as regiões geográficas e a inauguração de obras gigantes como Itaipu, até recentemente a maior unidade em operação no mundo. ${ }^{4}$ Para reverter as notórias deficiências de abastecimento e saneamento básico, em 1971, o governo militar lançou um plano nacional (PLANASA), o qual induziu as administrações municipais a concederem às empresas estaduais a operação dos serviços através de contratos de 25 ou 30 anos de duração. Houve um crescimento significativo do abastecimento de água entre 1970 e 1990 (de $60 \%$ para $86 \%$ dos domicílios urbanos), mas menos expressivo em termos de esgotamento sanitário (de $22 \%$ para $42 \%$ dos domicílios urbanos em termos de rede de coleta). A irrigação agrícola foi um dos pilares da Revolução Verde que fez do Brasil um dos principais exportadores do agronegócio mundial. Somada a uma irrigação de perfil empresarial no Centro-Sul, alimentada com subsídio governamental, a área de irrigação aumentou de forma acelerada no Nordeste, primeiro através de projetos públicos na década de 1970 e depois com investimentos privados com apoio público na segunda metade da década de 1980 (Souza, 1995).

O impulso industrializador, a partir de 1930, foi também marcado por evidentes contradições socioambientais no que diz respeito a uma exploração hídrica baseada em técnicas mal adaptadas às condições nacionais, dependente de financiamento externo e voltada fundamentalmente ao atendimento de demandas de uma parcela minoritária da sociedade. O patrimonialismo, institucionalizado desde o período colonial e que continuava a dominar a economia e a política do país, favorecendo aqueles que controlavam e eram suportados pelo braço do Estado (Faoro, 2001), fez com que os recursos hídricos passassem a ser estrategicamente utilizados na promoção de um desenvolvimento excludente e de alto custo social (na forma de impactos ambientais generalizados). ${ }^{5}$ A ausência de uma regulação ambiental efetiva servia como chamariz para atrair investimentos estrangeiros, em especial de indústrias altamente poluentes, o que foi epitomizado na célebre frase do Ministro Reis Velloso, em 1972: "nós temos ainda muito que poluir, eles [os países industrializados] não mais" (apud Guimarães, 1991: 130).

\footnotetext{
${ }^{4}$ Aproximadamente $83 \%$ do abastecimento eléctrico é hoje baseado no aproveitamento do potencial hidreléctrico (ANEEL, 2002).

5 Lembremos a lição de Kapp (1971), para o qual o capitalismo deve ser considerado como uma economia de custos sociais não pagos.
} 
Fase neoliberal: A água como mecanismo direto e indireto de acumulação $\mathrm{O}$ modelo econômico desenvolvimentista implantado na primeira metade do século XX - centrado na ação empresarial do Estado, segundo o ideário keynesiano - passou a ser objeto de concentrado criticismo desde o início dos anos 1970, não exatamente por parte daqueles que mais sofreram com as contradições socionaturais do desenvolvimento, mas pelos setores que identificaram na ação estatal, antes benéfica, a causa das taxas declinantes de rentabilidade do capital. Conhecida como crítica econômica neoliberal, inspirada em economistas como F.A. Hayek e M. Friedman, ganhou ainda mais vitalidade nos últimos anos com as oscilações do preço do petróleo, da taxa de juros, a globalização dos mercados e a crescente dificuldade de financiamento do déficit público. Entre os diversos axiomas ideológicos neoliberais podemos citar a concepção que a prosperidade dos países industrializados decorre da adoção irrestrita do livre mercado e, por conseguinte, caberia aos países em desenvolvimento seguir o mesmo exemplo (Chang e Grabel, 2004). A 'emergente' economia brasileira obviamente não esteve imune às pressões neoliberais, mas passou, como muitos outros países, por um processo de estabilização monetária, de reforma do mercado de trabalho, de deslocamento dos investimentos públicos e de agressiva atração de capital financeiro internacional.

A implantação do receituário neoliberal no Brasil vem sendo marcada por uma grande complexidade em termos de disputas dentro das classes sociais e de ajustes no bloco de poder, como descrito por Boito (2007). Por um lado, além do entusiasmo da classe média com o projeto neoliberal, a concessão de vantagens a algumas categorias (e.g. operários da indústria petroquímica) e a promoção de políticas compensatórias (como o programa 'bolsa-família') têm servido para neutralizar politicamente a classe trabalhadora. Por outro, os setores produtivos que foram excluídos no primeiro momento do Plano Real - editado em 1994 e de inspiração claramente neoliberal - passaram a se beneficiar mais diretamente após a desvalorização da moeda, em 1999, e com os estímulos oferecidos às cadeias exportadoras, notadamente ao agronegócio. Em que pese uma retórica de democracia e responsabilidade social, as reformas neoliberais buscam fundamentalmente atender às necessidades idiossincráticas de grupos e setores hegemónicos. O novo paradigma serve para remover barreiras e ineficiências que surgiram das próprias contradições de uma economia periférica, tecnologicamente subordinada e altamente dependente dos recursos naturais. Naturalmente que os impactos ambientais que passaram a afectar a viabilidade da atividade produtiva foram também sentidos pelo restante da sociedade, ${ }^{6}$ mesmo que

\footnotetext{
${ }^{6} \mathrm{Na}$ terminologia dos economistas ambientais, trata-se de uma externalidade econômica, embora o termo não traduza a dimensão social e ética da degradação ambiental.
} 
historicamente esta tenha tido uma menor participação nos resultados do desenvolvimento (ou seja, com a degradação do meio ambiente, as injustiças econômicas passam a ser também igualmente injustiças sociais).

A resposta neoliberal, além de não alterar os alicerces de longo prazo da exploração conjunta de sociedade e natureza, oportuniza ainda o surgimento de novas alternativas para a acumulação de capital - como o Protocolo Verde, lançado em 1995, um dispositivo que buscou "implementar mecanismos financeiros que complementassem e, ao mesmo tempo, criassem sinergias com a legislação ambiental existente" (Alimonda e Leão, 2005: 21). A advocacia de soluções baseadas em investimentos financeiros e em modernização tecnológica, com ênfase na qualidade das mercadorias e incentivos à competição, supostamente permitiria o enfrentamento da degradação ambiental sem a necessidade de mudanças nos padrões de produção, de consumo e de acumulação. Nesse sentido, a agenda ambientalista contemporânea deve ser também percebida como um subterfúgio que encobre a manutenção de práticas desiguais de apropriação dos recursos naturais e controle social estabelecidas desde o período colonial. Por outra parte, o avanço neoliberal sobre a natureza não pode ser visto como um fenómeno linear ou uniforme, mas como um processo em franco andamento e altamente sujeito a contestação e ajustes (Castree, 2008). No Brasil, a expansão neoliberal nunca serviu de empecilho para que os ramos mais tradicionais da economia pudessem continuar sem inflexões significativas (como no caso da expansão industrial em estados que agressivamente oferecem incentivos fiscais e regulatórios). Nos últimos anos, consolidou-se uma verdadeira dualidade nas políticas públicas e na atuação das agências governamentais, na medida que tanto se anunciam restrições a atividades em uma dada área geográfica, quanto se estimulam as mesmas atividades em regiões onde a resistência política é menor. A franca expansão do agronegócio em Mato Grosso talvez seja o melhor exemplo de tecnologias tidas como obsoletas, pelo seu alto nível de impacto ambiental, mas ainda perfeitamente viáveis em um mundo cada vez mais globalizado. Esse dualismo institucionalizado encontra guarida em publicações oficiais que tanto denunciam os impactos negativos do crescimento econômico, quanto exortam os agentes produtivos tradicionais (e.g. agricultura) a aumentarem a rentabilidade e reforçarem as vantagens comparativas já consolidadas (MMA, 2006).

Necessita-se identificar como os recursos hídricos passaram a fazer parte desse processo dual (i.e., ao mesmo tempo flexível e controlador) da agenda neoliberalizante. A complexa relação entre neoliberalismo e meio ambiente - na prática, uma verdadeira mistura de renovação e continuidade - serviu 
como a linha mestra das reformas institucionais voltadas ao uso e à conservação de recursos hídricos no Brasil. Em 1995, na esteira da reforma do Estado, o mesmo governo do Plano Real incluiu na estrutura ministerial a pasta de Meio Ambiente e Recursos Hídricos. Os primeiros anos da Secretaria de Recursos Hídricos, criada na estrutura do novo ministério, foram dedicados à negociação em torno do redesenho da base jurídica. Após vários anos de tramitação, a Lei da Política Nacional de Recursos Hídricos (Lei 9.433) foi promulgada em 1997, a qual incorporou diversos preceitos da metodologia internacional de gestão integrada preconizada por agências multilaterais. Os eixos da nova lei versam sobre a necessidade de se autorizar previamente a utilização da água (através do instrumento da outorga), o pagamento de taxas equivalentes ao impacto ambiental causado pelo uso (i.e., princípio do poluidor-pagador) e a constituição de comités de bacia hidrográfica (os chamados 'parlamentos da água'). Na sua primeira década de vigência, mais de 140 comités foram organizados e cerca de 10 mil profissionais passaram a trabalhar na implementação do Sistema Nacional de Gestão de Recursos Hídricos.

A justificativa moral e política para a nova configuração institucional baseia-se principalmente no conceito de 'escassez de recursos'. Tal conceito, obviamente, é também o princípio norteador da Ciência Econômica. Essa centralidade da noção de escassez para a introdução do novo marco regulatório de recursos hídricos não é mera coincidência, mas permite que toda uma racionalidade de viés ainda mais explicitamente capitalista seja sobreposta aos procedimentos de uso e conservação (trata-se da transição do recurso hídrico como mero repositório de 'valor de uso' para detentor, em si mesmo, de 'valor de troca' - cf. supra). Porém, escassez e abundância não são conceitos absolutos, mas somente fazem sentido em um contexto social e cultural determinado, muitas vezes organizado de forma a permitir o funcionamento de mercados (Harvey, 1973). Assim, a proclamada escassez de recursos hídricos no Brasil contemporâneo é o resultado de um processo de exploração do meio ambiente a serviço de um desenvolvimento desigual implantado ao longo de sua história.

Enquanto a Lei 9.433 tem sido falaciosamente apresentada como um marco de cidadania, esta nada mais é do que uma resposta neoliberal, com concessões democráticas menores e periféricas, às contradições causadas pela própria atividade econômica. Há, pelo menos, quatro áreas que demonstram claramente a afiliação das reformas institucionais no setor de recursos hídricos com os ajustes político-administrativos em andamento no país. Primeiramente, cabe reconhecer que o novo modelo produziu uma ampla burocratização da percepção dos problemas e um cientificismo 
artificial na formulação de respostas. Para uma questão poder ser reconhecida pelo sistema oficial, faz-se antes necessária sua transcrição em termos hidrológicos e tecnocráticos, o que serve como excelente caldo de cultura para a proliferação de consultorias e a ação de lobistas (para a relação entre gestão integrada e corrupção, ver Transparency International, 2008). ${ }^{7} \mathrm{Da}$ mesma forma, o processo de implantação dos comités e instrumentos de gestão depende quase sempre de apoio financeiro e aprovação política por parte do órgão hegemónico do sistema, a Agência Nacional de Águas (ANA). Formalmente, os comités seriam uma arena democrática e descentralizadora, mas na prática têm se constituído em mecanismos rígidos, hierarquizados e que servem aos grupos com maior força política (Valencio e Martins, 2004).

Em segundo lugar, a cobrança pelo uso da água, um dos principais instrumentos do novo modelo regulatório, ao invés de se tornar um incentivador da conservação ambiental e da realocação de recursos, vem operando como ratificadora do processo mais geral de mercadorização da natureza (Ioris, 2007b). A cobrança tem servido para ampliar a racionalidade ligada ao fetichismo das mercadorias, que resulta de uma reificação das relações sociais e socionaturais, imposta justamente pela condição de classe (cf. Lukács, 1971). Isso é demonstrado ao se constatar que a maioria dos novos comités de bacia teve suas atividades dominadas pela controvérsia em torno da introdução da cobrança, como no caso do CEIVAP no Rio Paraíba do Sul (cf. Formiga-Johnsson et al., 2007), em uma queda-de-braço entre os setores econômicos e funcionários do governo que pouco diz respeito aos interesses dos outros membros do comité. Além disso, ao invés de servirem para recuperar a condição dos corpos d'água, os valores arrecadados com a cobrança na Bacia do Rio Paraíba do Sul, a mais paradigmática experiência até agora no país, têm servido a projetos isolados, sem grande repercussão ambiental, mas ainda assim objetos de disputa acirrada entre prefeitos, Organizações Não-Governamentais e empreiteiros. Colateralmente, a cobrança opera como legitimadora de atividades historicamente responsáveis pela produção de impactos ambientais na bacia hidrográfica, as quais encontram nesse instrumento uma justificativa política para evitar um controle mais rigoroso por parte dos reguladores ambientais (Ioris, 2008).

Em terceiro lugar, a privatização de empresas públicas de água e energia eléctrica também representou um importante passo da escalada neoliberal sobre as águas no Brasil. O programa de desestatização brasileiro encontra-se entre os maiores do mundo, com uma transferência, até ao momento, de aproximadamente 100 mil milhões de dólares de ativos de empresas

$\overline{7}$ Para a relação entre gestão integrada e corrupção, ver Transparency International, 2008. 
públicas a operadores privados. Ao redor de $40 \%$ da geração hidreléctrica e grande parte da distribuição foram privatizados, totalizando um pagamento de 23,5 mil milhões de dólares (metade desse valor financiado pelo banco estatal BNDES). A privatização no setor hidreléctrico foi facilitada pela redução prévia de investimentos públicos (i.e., com menos investimentos, a qualidade do serviço se deteriorou e a oposição à privatização reduziu), cláusulas contratuais que protegem os operadores contra flutuações cambiais, reajuste de tarifas acima da inflação e remoção de subsídios a famílias de baixa renda (Pistonesi, 2005, apud Solanes e Jouravlev, 2006). Em 2003, foi aprovada a Lei 10.079/2004 que regulamenta a formação de parcerias público-privadas (PPP), mecanismo que tem se tornado a nova face da privatização no país.

Em contraste com o que se passou no setor eléctrico, a privatização do abastecimento de água e saneamento foi mais modesta, particularmente em função de pendências legais e da resistência organizada por entidades públicas e representações de consumidores. Até ao momento, apenas 3\% do serviço, o que corresponde ao atendimento de $5 \%$ da população nacional, foi privatizado (Britto e Silva, 2006). ${ }^{8}$ A grande oportunidade vislumbrada pelos operadores privados esteve relacionada à extinção dos contratos entre prefeituras e empresas estaduais, formalizados no âmbito do PLANASA. Dado o contexto neoliberal dos anos 1990, diversos prefeitos e alguns governadores agiram no sentido de não renovar os contratos, mas conceder os serviços a interessados privados, muitos controlados por empresas estrangeiras. Como no caso da hidroeletricidade, a privatização foi também favorecida pela redução de investimentos públicos: entre 1995 e 1998, apenas $\mathrm{R} \$ 1,8$ mil milhão foi investido, ao passo que $\mathrm{R} \$ 7,4$ mil milhões foram recebidos como pagamentos por empréstimos anteriores, $\mathrm{o}$ que significou um saldo retido de $\mathrm{R} \$ 5,7$ mil milhões (Oliveira Filho, 2006). De maneira geral, a privatização dos serviços de água no Brasil esteve diretamente associada a diversos conflitos entre operadores, reguladores públicos e clientes, com múltiplas evidências de distorções (Mello, 2001). Nas cidades onde houve privatização dos serviços, o processo pecou por uma notória falta de transparência e frequentes aumentos nas tarifas cobradas (Vargas, 2005).

Finalmente, cabe mencionar procedimentos menos óbvios de mercadorização dos recursos hídricos, como, por exemplo, a identificação de uma pretensa vocação da economia brasileira como exportadora de 'água virtual',

\footnotetext{
${ }^{8}$ A nova legislação de saneamento aprovada em 2007 (Lei 11.445), ao mesmo tempo que defende o direito básico a um serviço condizente, também incentiva a formação de PPPs.
} 
ou seja, a água necessária para produção de grãos e mercadorias. Defendido como um mecanismo de equalização hidrológica através do mercado internacional, o conceito de água virtual apenas transfere desequilíbrios e carências socionaturais, que são politicamente criados, para a arena mercantil, sem qualquer resolução dos problemas de fundo (Ioris, 2004). Existe também um crescente entusiasmo pelo pagamento de serviços ambientais, no que se inclui a protecção contra a erosão do solo e a manutenção do suprimento de água, baseado no princípio de que todos que se beneficiam de um mesmo ecossistema devem estar preparados para fazer pagamentos diretos àqueles que de alguma forma mantêm a estrutura física e ecológica do meio natural. Por exemplo, a manutenção de uma área vegetada a montante passaria a ser objeto de pagamento pelos usuários de água a jusante, que se beneficiam da floresta como garantia do caudal hidrológico. Como no mercado de carbono, para que o pagamento se torne realidade é preciso que se estime o valor monetário desse serviço ambiental (empregando técnicas de valoração ambiental e análise de custo-benefício). Porém, o pagamento pelos serviços ambientais está baseado na hipótese de que as populações locais são incapazes de perceber a importância de conservarem os recursos comuns e que somente tomariam uma atitude responsável se recebessem uma forma de incentivo, ou propina, em dinheiro (tal parece ser o argumento de Vosti et al., 2003 quanto à protecção da Bacia Amazónica). Ignora-se, assim, a longa interação dos grupos sociais com seu ambiente mais imediato, ao mesmo tempo que se desprezam pressões econômicas e políticas mais amplas.

\section{Conclusões}

Pode parecer quase axiomática a afirmação que o uso intensivo dos recursos hídricos desempenhou um papel fundamental na urbanização e no desenvolvimento agroindustrial brasileiro. Menos evidentes, porém, são as causas fulcrais e os desdobramentos dos múltiplos problemas relacionados à má gestão de grande parte das bacias hidrográficas nacionais. A retórica oficial tem empobrecido a qualidade do debate ao descrever os problemas de degradação ambiental como consequência apenas da falta de investimentos tecnológicos ou fruto de um comportamento individual irresponsável. O chamado 'novo modelo' institucional, introduzido pela Lei 9.433/1997 e influenciado pela doxa internacional de gestão integrada de bacias, alardeia a necessidade de compatibilização da demanda com a oferta de água, mas deixa de reconhecer a influência de diferenças sociais e espaciais na composição da demanda e na formação da oferta. Por detrás de uma construção simbólica dos problemas como responsabilidade coletiva, existe uma 
sistemática tentativa de desconhecer a problemática contemporânea de recursos hídricos como resultante de um processo de apropriação de recursos comuns e a serviço de um desenvolvimento desigual e excludente. Há um sem fim de exemplos que demonstram como esse vector dominante de exploração dos recursos hídricos se mantém intacto no alvorecer do século XXI, como na argumentação de Alegria (2008), na qual a fartura de água é mencionada como uma das mais importantes vantagens comparativas da maior economia emergente da América do Sul, o que tornaria o país uma verdadeira 'potência azul' (blue power).

Daí a necessidade de se construir uma análise capaz de interpretar os problemas de gestão dentro de um contexto de desigualdades políticas e socioeconômicas. As questões de recursos hídricos decorrem de uma determinada postura em relação à natureza e aos grupos sociais marginalizados. O uso dos recursos hídricos, seja como matéria-prima ou como potencial hidreléctrico e meio de transporte, esteve a serviço de um processo de acumulação econômica verticalizado, excludente e com um viés destruidor. Donde se deduz que a má utilização dos recursos hídricos está na verdade inserida no próprio conceito de desenvolvimento e, através da recente reforma institucional, reafirmada em tentativas sub-reptícias de tornar aceitáveis, e até mesmo lucrativos, os impactos desse mesmo desenvolvimento. Não há como compreender a origem e as tendências dos problemas socioambientais sem que se estabeleça uma relação ontológica entre passado, presente e futuro, assim como entre demandas locais, interações dentro da bacia hidrográfica e os efeitos de processos nacionais e internacionais. Pensar em uma gestão sustentável de recursos hídricos requer, portanto, uma visão politizada das causas e consequências de procedimentos e tecnologias, um entendimento das nuanças da correlação de forças em grupos sociais antagónicos. Somente por meio de uma hermenêutica crítica, alicerçada em um referencial de classe, será possível fazer as perguntas que realmente podem conduzir a respostas efetivas aos problemas de uso e conservação da água no Brasil.

\section{Referências bibliográficas}

Alegria, Rosa (2008), "Brazil 2018”, $4^{\text {th }}$ European Futurists Conference, 14-16 Outubro 2008, Lucerne.

Alimonda, Héctor; Leão, Sandro (2005), "As instituições financeiras federais e o Protocolo Verde", in Clélia Parreira e Héctor Alimonda (orgs.), As instituições financeiras públicas e o meio ambiente no Brasil e na América Latina. Brasília: FLACSO, 17-130. 
ANA (2007), A bistória do uso da água no Brasil. Do descobrimento ao século XX. Brasília: ANA.

ANEEL (1999), O estado das águas no Brasil. Perspectivas de gestão e informação de recursos hídricos. Brasília: MME/MMA/OMM.

ANEEL (2002), Atlas de energia elétrica do Brasil. Brasília: ANEEL.

Barbosa, Paulo; Braga, Benedito (2003), "Energy sector and water resources management in the new Brazilian private energy market", Water International, 28(2), 246-253.

Boito, Armando (2007), "Class relations in Brazil's new neoliberal phase”, Latin American Perspectives, 34, 115-131.

Britto, Ana Lúcia; Silva, Ricardo Toledo (2006), "Water management in the cities of Brazil. Conflicts and new opportunities in regulation", Urban Water Conflicts. An Analysis of the Origins and Nature of Water-related Unrest and Conflicts in the Urban Context. Paris: IHP/UNESCO, 39-51.

Castree, Noel (2008), "Neoliberalising nature. The logics of deregulation and reregulation”, Environment and Planning A, 40, 131-152.

Chang, Ha-Joon; Grabel, Ilene (2004), Reclaiming Development: An Alternative Economic Policy Manual. London/New York: Zed Books.

Davis, Mike (2004), "The political ecology of famine. The origins of the Third World”, in Richard Peet; Michael Watts (orgs.), Liberation Ecologies: Environment, Development, Social Movements. London/New York: Routledge, 48-63 [2ª ed.].

Ekers, Michael; Loftus, Alex (2008), “The power of water. Developing dialogues between Foucault and Gramsci”, Environment and Planning D, 26, 698-718.

Faoro, Raymundo (2001), Os Donos do Poder: Formação Histórica do Patronato Político Brasileiro. São Paulo: Globo [2 $\left.{ }^{\mathrm{a}} \mathrm{ed}.\right]$.

Formiga-Johnsson, Rosa Maria et al. (2007), "The politics of bulk water pricing in Brazil. Lessons from the Paraíba do Sul Basin”, Water Policy, 9, 87-104.

Foster, John Bellamy (2000), Marx's Ecology: Materialism and Nature. New York: Monthly Review Press.

Furtado, Celso (2007), Formação Econômica do Brasil. São Paulo: Companhia das Letras [34 a ed.].

Gramsci, Antonio (1971), Selections from the Prison Notebooks of Antonio Gramsci. London: Lawrence \& Wishart.

Guimarães, Roberto (1991), The Ecopolitics of Development in the Third World: Politics and Environment in Brazil. Boulder/London: Lynne Rienner.

Harvey, David (1973), Social Justice and the City. London: Edward Arnold.

Harvey, David (2006), The Limits to Capital. London/New York: Verso [2 ed.].

Hickey, Samuel; Mohan, Giles (orgs.) (2004), Participation: From Tyranny to Transformation. London/New York: Zed Books.

Holanda, Sérgio Buarque (2000), Visão do paraíso: Os motivos edênicos no descobrimento e colonização do Brasil. São Paulo: Brasiliense [2 ${ }^{a}$ ed.]. 
Ioris, Antônio Augusto Rossotto (2004), "Virtual water in an empty glass. The geographical complexities behind water scarcity”, Water International, 29(1), 119-121.

Ioris, Rafael Rossotto (2007a), "Agrandando el pastel. Políticas de desarollo, nacionalismo y relaciones exteriores en el Brasil de los años cincuenta", Foro Internacional, 188, 340-368.

Ioris, Antônio Augusto Rossotto (2007b), "The headwaters of water problems in Brazil. Commodification and exclusion”, Capitalism Nature Socialism, 18(1), 28-50.

Ioris, Antônio Augusto Rossotto (2008), "The limits of integrated water resources management. A case study of Brazil's Paraíba do Sul River Basin”, Sustainability, Science, Practice E Policy, 4(2), 4-11.

IPEA (2008), PNAD - 2007: Primeiras análises: Saneamento básico e babitação. Comunicado da Presidência do Instituto de Pesquisa Econômica Aplicada, Número 13, 21 de Outubro de 2008.

Kapp, Karl William (1971), The Social Costs of Private Enterprise. New York: Schoken Books.

Kovel, Joel (2002), The Enemy of Nature: The End of Capitalism or the End of the World? London/New York: Zed Books.

Lukács, György (1971), History and Class Consciousness: Studies in Marxist Dialectics. London: Merlin Press.

Marx, Karl (1996), Capital. Volume I. Karl Marx \& Frederick Engels Collected Works, Número 35. London: Lawrence \& Wishart [1867].

Marx, Karl (1998), Capital. Volume III. Karl Marx \& Frederick Engels Collected Works, Número 37. London: Lawrence \& Wishart [1894].

Marx, Karl; Engels, Friedrich (1974), The German Ideology. London: Lawrence \& Wishart [1846].

Mello, Marina Figueira (2001), Privatização do setor de saneamento no Brasil: Quatro experiências e muitas lições. Rio de Janeiro: Departamento de Economia/PUC-RJ.

MMA (2006), Plano nacional de recursos hídricos. Brasília: Ministério do Meio Ambiente.

Mollinga, Peter Paul (2008), "Water, politics and development. Framing a political sociology of water resources management", Water Alternatives, 1(1), 7-23.

O'Connor, James (1998), Natural Causes: Essays in Ecological Marxism. New York/London: The Guilford Press.

Oliveira Filho, Abelardo (2006), "Institucionalização e desafios da política nacional de saneamento: Um balanço”, Proposta, 110, 12-23.

Polanyi, Karl (2001), The Great Transformation: The Political and Economic Origins of Our Time. Boston: Beacon Press [3 $3^{a}$ ed.; $\left.{ }^{1} 1944\right]$.

Prado Júnior, Caio (1977), Formação econômica do Brasil contemporâneo. São Paulo: Brasiliense [15 a ed.].

Smith, Neil (2007), "Nature as accumulation strategy" in Leo Panitch; Colin Leys (orgs.), Socialist Register: Coming to Terms with Nature. London: Merlin Press, 16-36. 
Smith, Neil (2008). Uneven Development: Nature, Capital, and the Production of Space. Athens, GA/London: University of Georgia Press [3 ${ }^{\mathrm{a}} \mathrm{ed}$.].

Solanes, Miguel; Jouravlev, Andrei (2006), Water Governance for Development and Sustainability. Santiago, Chile: CEPAL.

Souza, Hermino Ramos (1995), "Agricultura irrigada no semi-árido nordestino", in Gustavo Maia Gomes et al. (orgs.), Desenvolvimento sustentável no Nordeste. Brasília: IPEA, 195-236.

Swyngedouw, Erik (2004), Social Power and the Urbanization of Water: Flows of Power. Oxford: Oxford University Press.

Transparency International (2008), Global Corruption Report 2008: Corruption in the Water Sector. Cambridge: Cambridge University Press.

Valencio, Norma Felicidade Lopes da Silva; Martins, Rodrigo Constante (2004), "Novas institucionalidades na gestão de águas e poder local. Os limites territoriais da democracia decisória”, Interações, 5(8), 55-70.

Vargas, Marcelo Coutinho (2005), O negócio da água. Riscos e oportunidades das concessões de saneamento à iniciativa privada: Estudos de caso no Sudeste Brasileiro. São Paulo: Annablume.

Vosti, Stephen et al. (2003), "Rights to forest products, deforestation and smallholder income. Evidence from the western Brazilian Amazon”, World Development, 31(11), 1889-1901.

Žižek, Slavoj (2008), In Defence of Lost Causes. London/New York: Verso. 